\title{
PENGARUH BRAND SATISFACTION, BRAND TRUST, DAN BRAND EXPERIENCE TERHADAP BRAND LOYALTY KOMPAS DIGITAL
}

\author{
Ignatius Aditya \\ Program Studi Magister Manajemen Universitas Tarumanagara \\ adit00762@yahoo.com \\ Miharni Tjokrosaputro \\ Program Studi Magister Manajemen Universitas Tarumanagara
}

\begin{abstract}
This research was conducted in order to assess the effect of brand satisfaction, brand trust, and brand experience to brand loyalty of Kompas digital. The research implemented quantitative method, in which questionnaire were distributed to a total of 150 respondents, thus enabling the data to be analyzed. Data were collected from respondents in Jakarta regions. Data were analyzed by SPSS version 21.00 for windows using multiple linier regression method. After conducting data analysis, it was revealed that brand satisfaction and brand experience individually have a positive impact on brand loyalty. Meanwhile brand trust doesn't have a positive impact toward brand loyalty. But all three variables simultaneously have a significant effect toward brand loyalty.
\end{abstract}

\begin{abstract}
Abstrak : Penelitian ini dilakukan untuk menilai pengaruh kepuasan merek, kepercayaan merek, dan pengalaman merek terhadap loyalitas merek Kompas digital. Penelitian ini menerapkan metode kuantitatif, di mana kuesioner dibagikan kepada total 150 responden, sehingga memungkinkan data untuk dianalisis. Data dikumpulkan dari responden di wilayah Jakarta. Data dianalisis dengan SPSS versi 21.00 untuk windows menggunakan metode regresi linier berganda. Setelah melakukan analisis data, diketahui bahwa kepuasan merek dan pengalaman merek secara individu memiliki dampak positif terhadap loyalitas merek. Sementara kepercayaan merek tidak memiliki dampak positif terhadap loyalitas merek. Namun ketiga variabel tersebut secara simultan memiliki pengaruh yang signifikan terhadap loyalitas merek.
\end{abstract}

Keywords : Brand Satisfaction, Brand Trust, Brand Experience, Brand Loyalty

\section{PENDAHULUAN}

Setiap hari jutaan tak terhitung banyaknya orang di seluruh dunia mengikuti berita harian yang ditampilkan oleh media - media utama. Media massa dan pers merupakan industri yang yang telah ada selama berabad - abad. Di Indonesia salah satu media massa dan pers yang terkenal adalah Kompas.

Namun berdasarkan laporan dari $\mathrm{CNN}$, frekuensi membaca orang Indonesia rata rata hanya tiga sampai empat kali per minggu. Dan jumlah buku yang dibaca hanya lima sampai sembilan per tahun sehingga menjadikan Indonesia sebagai salah satu negara dengan minat baca yang terendah di duniaPadahal menurut salah satu artikel kompas, penetrasi internet di Indonesia mencapai 50\% dengan waktu bervariasi, dimulai dari $1-3$ jam per hari hingga lebih dari 7 jam per hari. Hal ini tentu jauh lebih lama daripada waktu yang dihabiskan untuk membaca.

Kompas sebagai salah satu media terkemuka di Indonesia berusaha untuk tetap relevan dan menjadi media yang dapat dipercaya di internet dengan meluncurkan konten digitalnya. Menghadirkan konten yang dapat memenuhi kepuasan konsumen sangatlah penting bagi Kompas. Menurut Horppu, Kuivalainen, Tarkiainen, \& Ellonen (2008) “web site satisfaction could be viewed as a set of items relating a user's satisfaction and positive experiences with 
the online content, structure, presentation, and service." Namun jika konsumen melihat secara online, ada banyak website dan media berita yang dapat membuat konten digitalnya dengan lebih baik, user friendly, dan menarik. Karena itu Kompas perlu memperhatikan dengan bijak apa yang ditampilkan di layarnya.

Menurut Rios \& Riquelme (2008), brand trust dapat memainkan peranan yang penting dalam layanan online dibanding toko fisik karena dunia online pada dasarnya tidak berwujud dan konsumen tidak dapat menggunakan / menyentuhnya nya secara fisik untuk menyimpulkan kepercayaan. Menurut CNN terdapat lebih dari 800 ribu situs website yang menyebarkan berita bohong atau hoax di Indonesia. Agar konsumen dapat terus menerus menggunakan layanan Kompas, maka Kompas juga perlu untuk meningkatkan loyalitas konsumen. Horppu, Kuivalainen, Tarkiainen, \& Ellonen (2008) " it is suggested that loyalty of the consumers has become a key success factor in a competitive and an economic sense for e-commerce providers as competition is only a "mouse-click" away." Jadi menciptakan loyalitas sangatlah penting karena konsumen dapat melakukan pembelian berulang. Tujuan dari penelitian ini adalah untuk mengetahui pengaruh atau dampak dari brand satisfaction, brand trust, dan brand experience terhadap brand loyalty kompas digital di Jakarta.

\section{TINJAUAN PUSTAKA}

Merek

Merek menurut Kotler \& Keller (2016) adalah sebuah nama, istilah, simbol, desain, atau kombinasi darinya yang bertujuan untuk mengindentifikasi barang atau jasa dari seorang penjual terhadap penjual lainnya dan untuk membedakan diri dari pesaing. Tidak semua produk memiliki merek, dan kita dapat menemukan banyak produk yang tidak bermerek di dunia ini. Kotler (2016) mendefinisikan sebuah produk sebagai apa saja yang bisa ditawarkan kepada sebuah pasar untuk memuaskan keinginan atau kebutuhan, termasuk barang fisik, layanan, properti, informasi, ide, dsb.

\section{Brand Satisfaction}

Menurut Kotler \& Keller (2016) kepuasan (satisfaction) adalah perasaan seseorang yang mengambarkan rasa puas dan kecewa dari membandingkan kinerja atau hasil produk yang dirasakan berkaitan dengan harapannya. Apabila performa dan hasil suatu produk yang dikonsumsi melebihi harapan seorang konsumen, maka ia akan merasa puas. Dan jika sebaliknya yang terjadi maka konsumen tersebut akan merasa tidak puas. Sahin, Zehir, \& Kitapci (2011) mengatakan bahwa "Satisfaction is a positive affective reaction to an outcome of a prior experience." Pelanggan merasa puas bila pengalaman yang diterimanya positif.

\section{Brand Trust}

Menurut Sahin et al. (2011) mengatakan "Brand trust is defined as the willingness of the average consumer to rely on the ability of the brand to perform its stated function". Kepercayaan terhadap merek menunjukan kredibilitas merek tersebut sehingga pembelian berulang lebih mungkin untuk dilakukan oleh konsumen. Berdasarkan halaman yang dikutip dari jurnal Ashley dan Leonard (2009), "Consumers, develop trust in a brand based on positive beliefs regarding their expectation for the behavior of the organization and the performance of products a brand represents". Menurut Kim, Ferrin, \& Rao (2009) brand trust bahkan lebih penting lagi dalam e-commerce dan penjualan online.

\section{Brand Experience}

Brand experience dalam tulisan yang dimuat di jurnal ilmiah oleh Huang (2017) disebutkan sebagai tanggapan konsumen secara internal (sensasi, perasaan, kognisi, dan perilaku) yang ditimbulkan oleh rangsangan terkait merek yang merupakan bagian dari 
identitas merek seperti pengemasan, komunikasi, dan lingkungan yang dapat berdampak positif ataupun negatif terhadap perilaku konsumen.

\section{Brand Loyalty}

Menurut Kotler (2016), loyalty adalah komitmen untuk membeli kembali atau mempromosikan sebuah produk atau jasa yang telah dikonsumsi. Loyalitas merek memberikan keamanan melalui permintaan yang bisa diprediksi oleh perusahaan dan menciptakan hambatan bagi pesaing lain untuk berkompetisi. Menurut Gary Salegna (2018) loyalitas pelanggan juga dapat dapat diarahkan dari loyalitas merek yang dibuat penyedia layanan dengan toko fisik ke layanan online. Seiring waktu pelanggan yang merasakan hubungan emosional dengan perusahaan dapat menjadi lebih loyal.

Berdasarkan pemaparan di atas, hipotesis yang diajukan dalam penelitian ini adalah sebagai berikut:

\section{$\mathrm{H}_{1}$ : Online satisfaction Kompas digital memiliki pengaruh positif terhadap brand loyalty Kompas \\ $\mathrm{H}_{2}$ : Online trust dari Kompas digital memiliki pengaruh positif terhadap brand loyalty Kompas \\ $\mathrm{H}_{3}$ : Online experience Kompas digital berhubungan positif dengan brand loyalty Kompas}

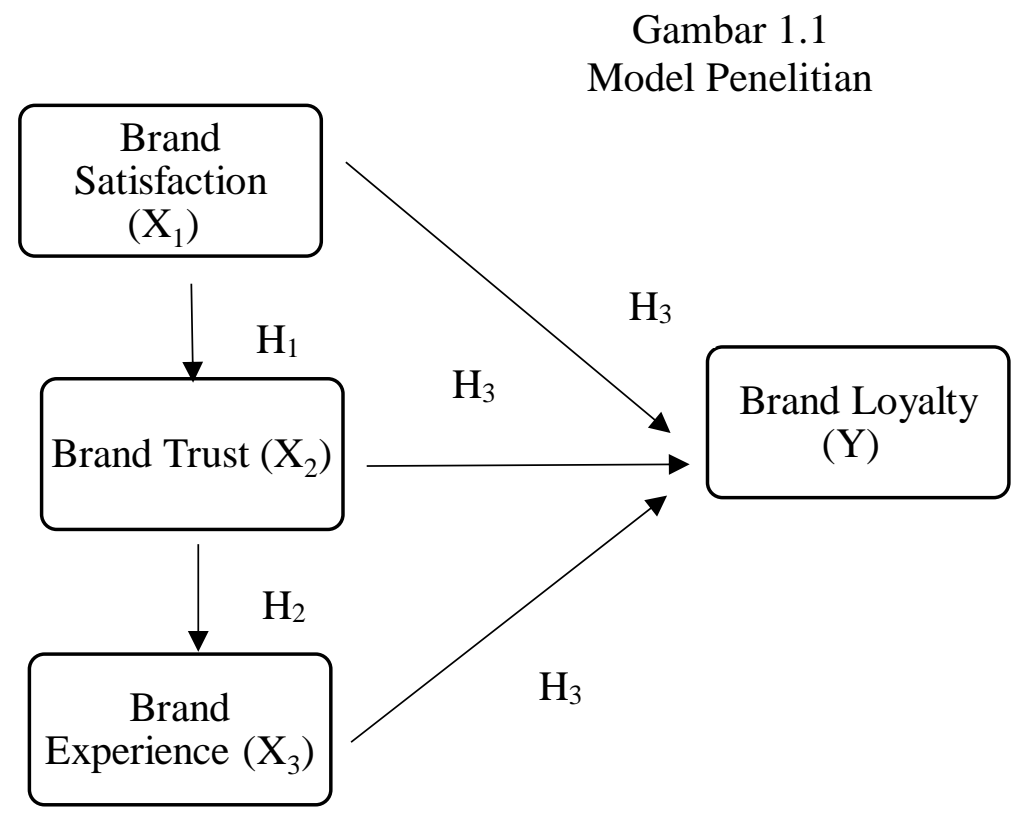

\section{Metode Penelitian}

Terdapat beberapa metode penelitian yang dapat digunakan untuk karya ilmiah. Menurut Noor (2016) terdapat tiga jenis rancangan penelitian yaitu penelian eksploratif, penelitian konklusif, dan penelitian deskriptif. Dalam penelitian ini, peneliti mengambil metode penelitian deskriptif secara kuantitatif yang bertujuan untuk mendeskripsikan sifat atau karakteristik dari suatu gejala, peristiwa, dan kejadian yang terjadi saat ini. Penelitian ini dapat bekerja pada lebih dari satu variabel. dan didasarkan pada jangka waktu cross sectional. Artinya Studi ini dilakukan dengan pengambilan data sebanyak satu kali selama satu periode Peneliti menyebarkan kuesioner kepada 150 orang responden di Jakarta pada tahun 2018 secara acak yang pernah membaca koran kompas secara online dan offlline di daerah DKI Jakarta. 


\section{Hasil Analisis Data}

Dalam analisis regresi berganda dilakukan tiga jenis pengujian yaitu uji-F (uji simultan), uji-t (uji parsial), dan koefisien determinasi ganda dengan menggunakan program SPSS version 21.00 for windows. Adapun persamaan regresi menghasilkan model persamaan regresi Brand Loyalty $(\mathrm{Y})=-0,959+0,695(\mathrm{X} 1$, Brand Satisfaction $)+-0,193(\mathrm{X} 2$, Brand Trust $)+0,421(\mathrm{X} 3$, Brand Experience). Dari persamaan ini, diketahui variabel yang memiliki pengaruh paling besar terhadap keputusan pembelian adalah Brand Satisfaction (X1) dengan koefisien regresi sebesar 0,695. Sementara variabel yang memiliki pengaruh paling kecil terhadap keputusan pembelian adalah Brand Trust (X3) dengan koefisien regresi sebesar 0,193. Sedangkan variabel Brand Experience (X3) memiliki nilai koefisien regresi sebesar 0,421.

Dari hasil uji F (uji simultan) diperoleh nilai signifikansi sebesar $0,000<0,05$. Artinya terdapat secara simultan terdapat pengaruh yang signifikan antara brand satisfaction (X1), brand trust (X2), dan brand experience (X3) terhadap brand loyalty (Y). Dari hasil uji $\mathrm{t}$ (uji parsial), nilai signifikansi untuk variabel brand satisfaction (X1) sebesar $0,00<0,05$, brand trust (X2) sebesar 0,112 >0,05, dan brand experience (X3) sebesar $0,00<0,05$.

Tabel 1.2

Rangkuman Hipotesis

\begin{tabular}{|l|l|l|}
\hline Nomor & Hipotesis & $\begin{array}{l}\text { Ditolak / Tidak } \\
\text { Ditolak }\end{array}$ \\
\hline 1 & $\begin{array}{l}\text { Brand satisfaction memiliki pengaruh positif } \\
\text { terhadap brand loyalty Kompas digital }\end{array}$ & Tidak Ditolak \\
\hline 2 & $\begin{array}{l}\text { Brand trust memiliki pengaruh positif terhadap } \\
\text { brand loyalty Kompas digital }\end{array}$ & Ditolak \\
\hline 3 & $\begin{array}{l}\text { Brand experience memilik pengaruh positif dengan } \\
\text { brand loyalty Kompas digital }\end{array}$ & Tidak Ditolak \\
\hline
\end{tabular}

\section{Kesimpulan dan Saran}

Berdasarkan hasil pembahasan dan hasil penelitian pada bab sebelumnya, maka kesimpulan yang dapat kita ambil adalah sebagai berikut:

1. Terdapat pengaruh yang positif antara brand satisfaction terhadap brand loyalty Kompas digital.

2. Tidak terdapat pengaruh yang positif antara brand trust terhadap brand loyalty Kompas digital.

3. Terdapat pengaruh yang positif antara brand experience terhadap brand loyalty Kompas digital.

Terkait dengan hasil penelitian ini maka peneliti memberi beberapa saran yang dapat bermanfaat bagi perusahaan dan peneliti lain.

1. Bagi perusahaan

Peneliti menyarankan agar Kompas memanfaatkan kelebihan dimensi sensorik (panca indera) dari brand experience yang dirasakan pelanggan. Hal ini berdasarkan survey bahwa mayoritas responden paling banyak memberikan pendapat "Sangat Setuju" pada pernyataan bahwa "Kompas memiliki impresi yang mudah dikenali secara visual".

2. Bagi penelti selanjutnya

Bagi peneleti selanjutnya disarankan agar penelitian ini dapat dikembangkan lagi dengan menambah variabel lainnya yang belum tercakup dalam penelitian ini misalkan website environment (Lin \& Lee, 2012), covert content and consumer-brand relationships price (Ashley, Christy \& Leonard, 2009) dan lain - lainnya. Serta menambah jumlah sampel, cakupan wilayah, dan variasi demografinya. 


\section{Daftar Pustaka}

Ashley, Christy And Leonard, Hillary A.. (2009), "Betrayed by The Buzz? Covert Content and Consumer-Brand Relationships", Journal of Public Policy and Marketing, Vol.28, 2, p.212-220.

Horppu, M., Kuivalainen, O., Tarkiainen, A., \& Ellonen, H. K. (2008). Online satisfaction, trust, and loyalty, and the impact of the offline parent brand. Journal of Product and Brand Management, 17(6), 403 - 413.

Huang, C. (2017). The impacts of brand experiences on brand loyalty: mediators of brand love and trust. Management Decision, 55(5), 915-934. doi:10.1108/md-10-2015-0465

Kim, D. J., Ferrin, D. L., \& Rao, H. R. (2009). Trust and satisfaction, two stepping stones for successful e-commerce relationships: a longitudinal exploration. Information System Research, 20(2), 237 - 257.

Kotler, P., \& Keller, K. L. (2016). Marketing management (15th ed.). Hagerstown, WA: Pearson.

Lin, M. Q., \& Lee, B. C. (2012). The influence of website environment on brand loyalty: brand trust and brand affect as mediators. International Journal of Electronic Business Management, 10(4), 308 - 321.

Noor, J. (2017). Metodologi penelitian: skripsi, tesis, disertasi \& karya ilmiah. Jakarta, Indonesia: Kencana.

Rios, R. E., \& Riquelme, H. E. (2008). Brand equity for online companies. Marketing Intelligence \& Planning, 26(7), 719 - 742.

Sahin, A., Zehir, C., \& Kitapci, H. (2011). The effects of brand experience, trust, and satisfaction on building brand loyalty; an empirical research on global brands. International Strategic Management Conference, 7, 1288 - 1301.

Salegna, G. (2018). Classification model and e-loyalty implications for online services. International Journal of Quality and Service Sciences, 10(1), 72-83. 